\title{
Bioactive Compounds from Artemisia campestris L. Subsp. Campestris
}

\author{
BIANCA IVANESCU르, CRISTINA LUNGU*, LAURIAN VLASE², ANA MARIA GHELDIU², CRISTINA GRIGORESCU3*, \\ ANDREIA CORCIOVA 4 \\ ${ }^{1}$ Grigore T. Popa University of Medicine and Pharmacy, Faculty of Pharmacy, Department of Pharmaceutical Botany, 16 Universitatii \\ Str., 700115, lasi, Romania \\ IJuliu Hatieganu University of Medicine and Pharmacy, Faculty of Pharmacy,Department of Pharmaceutical Technology and \\ Biopharmacy, 8 Victor Babes Str., 400010, Cluj Napoca, Romania \\ ${ }^{3}$ GrigoreT. Popa University of Medicine and Pharmacy, Faculty of Medicine, Department of Thoracic Surgery, 16 Universitatii Str., \\ 700115, lasi, Romania \\ ${ }^{4}$ GrigoreT. Popa University of Medicine and Pharmacy, Faculty of Pharmacy, Department of Drug Analysis, 16 Universitatii Str., \\ 700115, lasi, Romania
}

\begin{abstract}
Artemisia campestris L. (field wormwood) is a known medicinal plant used mainly in Asian medicine and most often overlooked in the western world, despite its cosmopolitan distribution. The aim of this study was to investigate the phytochemical composition of $A$. campestris from Romanian spontaneous flora in order to determine the bioactive molecules and to assess the antioxidant effect of the plantextract. For this purpose, we applied LC-MS methods for the analysis of phytosterols and polyphenols and developed new methods for the analysis of methoxylated flavones and sesquiterpene lactones, specific compounds in Artemisia genus. The paper is the first to report the concentration of these compounds in the indigenous plantand also to identify some new compounds, previously not reported in this species, such as eupatorin, casticin, and acacetin. The plant extract showed significant antioxidant activity in both radical scavenging and reducing power assay, well correlated with the polyphenolic profile.
\end{abstract}

Keywords: LC-MS, methoxylated flavonoids, phytosterols, polyphenols.

Artemisia genus includes over 400 species, many of which are well-known medicinal and aromatic plants, used for their analgesic, anti-inflammatory, antispasmodic, antimalarial, antimicrobial, anthelmintic, hepatoprotective, antidiabetic, antiulcer, anticancer properties [1]. The importance of Artemisia genus is still discovered, new therapeutic approaches are investigated and the area of therapeutic potential is extended. Recently, it was proved that some Artemisia sp. inhibitacetylcholinesterase activity, a target for treatment of myasthenia gravis (an autoimmune disease), glaucoma, Parkinson's disease, dementia [2, 3].

Artemisia campestris $\mathrm{L}$. is a perennial plant distributed to Eurasia, North Africa and North America. Romanian flora contains three subspecies: alpina, campestris and lednicensis, from which subsp. campestris is frequently encountered [4]. A. campestris flowers and leaves were traditionally used as hypoglycaemic, cholagogue, choleretic, antivenin, anti-inflammatory, anti-rheumatic, antimicrobial, diuretic, antilithiasic, for the treatment of obesity and to decrease cholesterol levels $[5,6]$.Most phytochemical studies carried out to date analyzed the composition of volatile oil that differs according to plant source and variety [7-9]. Other studies mention the presence of alkaloids, saponins, coumarins, terpenes, flavonoids $[1,6]$ and fatty acids [10]. The only information regarding the chemical composition of Romanian plants refers to the quantity $(0.05 \mathrm{~mL} / 100 \mathrm{~g})$ and components of essential oil [8]. Numerous studies confirm the biological activities of $A$. campestris such as antimicrobial, anthelmintic, antioxidant, antitumor, antidiabetic, hepatoprotective, nephroprotective, insecticidal, antivenomous, antiulcer and allelopathic [5, 11-13].

Considering the therapeutic potential, the large distribution in the spontaneous flora and the scarcity of chemical information regarding the Romanian species, we attempted a phytochemical screening of $A$. campestris subsp. campestris using LC-MS analysis. The study was focused on the following bioactive compounds: polyphenols - with emphasis on methoxylated flavones, phytosterols and sesquiterpene lactones. The antioxidant activity of the extract was also assessed through two antioxidant tests.

\section{Experimental part \\ Matherials and methods \\ Plant material and extraction procedure}

The aerial parts of Artemisia campestris subsp. campestris were harvested at the flowering stage from the countryside around lasi, Romania, in September 2014. The species was identified by a specialist (biologist $C$. Mardari, PhD) from the Botanical Garden A. Fatu lasi and a voucher specimen was deposited in the Herbarium of Pharmaceutical Botany Department from Grigore T. Popa University of Medicine and Pharmacy. The plants were airdried at room temperature and grounded to a fine powder. $10 \mathrm{~g}$ of plant material was extracted three times with 200 $\mathrm{mL}$ methanol for 1 hour, at room temperature, using a magnetic stirrer. The extract was appropriately diluted before injection in HPLC.

Chromatographic conditions for polyphenols analysis

Polyphenols were quantified using a HPLC-UV-MS method, previously described [14]. Eighteen polyphenolic standards were used: caffeic acid, chlorogenic acid, pcoumaric acid, kaempferol, apigenin, rutin, quercetin, quercitrin, isoquercitrin, fisetin, hyperoside, myricetin (Sigma, Germany), ferulic acid, gentisic acid, sinapic acid, patuletin, luteolin (Roth, Germany), caftaric acid (Dalton, USA).Calibration curves in the $0.5-50 \mu \mathrm{g} / \mathrm{mL}$ range with 
good linearity $\left(R^{2}>0.999\right)$ were used to determine the concentration of polyphenolsin plant samples.Samples were analyzed before and after hydrolysis in order to identify the flavonoidic glycosides and also flavonoid aglycones released after hydrolysis. Four polyphenols cannot be quantified in current chromatographic conditions due to overlapping (caftaric acid with gentisic acid and caffeic acid with chlorogenic acid). However, all four compounds can be selectively identified in MS detection (qualitative analysis) based on differences between their molecular mass and MS spectra.

Chromatographic conditions for the analysis of caffeic and chlorogenic acids

Seeing that caffeic and chlorogenic acids, important antioxidants, could only be identified, but not quantified in the previous chromatographic conditions, we carried out a new analysis in order to determine the quantity of these two hydroxycynnamic acids. The compounds were separated using a Zorbax SB-C18 reversed-phase analytical column (100 $\times 3.0 \mathrm{~mm}$ i.d., $3 \mu \mathrm{m}$ particles) fitted with a guard column Zorbax SB-C18, both operated at $42^{\circ} \mathrm{C}$. The separation was achieved under isocratic conditions using a mobile phase consisting of $0.1 \%$ aceticacid andacetonitrile (v/v). The flow rate was $0.8 \mathrm{~mL} / \mathrm{min}$ and the injection volume was $5 \mu \mathrm{L}$. Mass spectrometry analysis was performed on an Agilent Ion Trap $1100 \mathrm{VL}$ mass spectrometer with electrospray ionization (ESI) interface in negative mode. Operating conditions were optimized in order to achieve maximum sensitivity values: gas (nitrogen) temperature $60^{\circ} \mathrm{C}$ at a flow rate of $12 \mathrm{~L} / \mathrm{min}$, nebulizer pressure $60 \mathrm{psi}$ and capillary voltage $+3500 \mathrm{~V}$. The full identification of compounds was performed by comparing the retention times and mass spectra with those of standards in the same chromatographic conditions. To avoid or limit the interference from background, the multiple reactions monitoring analysis mode was used instead of single ion monitoring (e.g., MS/ MS instead of MS). Calibration curves of the hydroxycynnamic acids in the range of selected concentrations $(0.06-4 \mu \mathrm{g} / \mathrm{mL})$ showed a good linear correlation coefficient $\left(R^{2}>0.99\right)$.

Chromatographic conditions for the analysis of methoxylated flavones

Methoxylated flavonoid aglycones were quantified through high-performance liquid chromatography coupled with mass spectrometry (LC-MS), using six standards: jaceosidin, eupatilin (ALB Technology, China), casticin, acacetin, eupatorin, hispidulin (Sigma, Germany). The separation of the methoxylated flavones was achieved using a Zorbax SB-C18 reversed-phase analytical column ( $100 \times 3.0 \mathrm{~mm}$ i.d., $5 \mu \mathrm{m}$ particle) fitted with a guard column Zorbax SB-C 18 , both operated at $48^{\circ} \mathrm{C}$. The mobile phase consisted in $0.1 \%$ (v/v)aceticacid andmethanol with the following gradient: beginning with $45 \%$ methanol and ending at $50 \%$ methanol, for 8 minutes with a flow rate of $0.9 \mathrm{~mL} / \mathrm{min}$ and an injection volume of $5 \mu \mathrm{L}$. For the MS analysis the following optimized conditions were used: electrospray ionization (ESI) interface operating in negative mode, gas (nitrogen) temperature $325^{\circ} \mathrm{C}$ at a flow rate of $12 \mathrm{~L} / \mathrm{min}$, nebulizer pressure $60 \mathrm{psi}$ and capillary voltage + $2500 \mathrm{~V}$. The full identification of compounds was performed by comparing the retention times and mass spectra with those of standards in the same chromatographic conditions. The MS was operated in the multiple reactions monitoring analysis (MRM) mode instead of single ion monitoring. Calibration curves in the $0.02-6 \mu \mathrm{g} / \mathrm{mL}$ range with good linearity $\left(R^{2}>0.99\right)$ were used todetermine the concentration of methoxylated flavones.

Chromatographic conditions for the analysis of phytosterols

Quantification of sterols was performed by a LC-MS method previously described [15], using five standards: $\beta$ sitosterol, stigmasterol, campesterol, brassicasterol and ergosterol, acquired from Sigma (Germany). Calibration curves of the sterols in the range of selected concentrations $(0.06-6 \mu \mathrm{g} / \mathrm{mL})$ showed a linear correlation coefficient $\left(R^{2}>\right.$ 0.99)

Chromatographic conditions for the analysis of sesquiterpene lactones

The analysis of sesquiterpene lactones was carried out byhigh-performance liquid chromatography coupled with mass spectrometry (LC-MS), using six standards: vulgarin, á-santonin, dehidroleucodine, artemisinin, costunolide and alantolactone (Sigma, Germany). The compounds were separated using a Zorbax SB-C18 reversed-phase analytical column ( $100 \times 3.0 \mathrm{~mm}$ i.d., $5 \mu \mathrm{m}$ particles) fitted with a guard column Zorbax SB-C18, both operated at $48^{\circ} \mathrm{C}$. The mobile phase consisted in $0.1 \%(\mathrm{v} / \mathrm{v})$ acetic acid and methanol with the following gradient: beginning with $45 \%$ methanol and ending at $80 \%$ methanol, for 8 min with a flow rate of $0.8 \mathrm{~mL} / \mathrm{min}$ and an injection volume of $5 \mu \mathrm{L}$.

Mass spectrometryanalysis was performed on an Agilent Ion Trap $1100 \mathrm{VL}$ mass spectrometer with atmospheric pressure chemical ionization $(A P C I)$ interface in positive ion mode. Operating conditions were optimized in order to achieve maximum sensitivity values: gas (nitrogen) temperature $250^{\circ} \mathrm{C}$ at a flow rate of $7 \mathrm{~L} / \mathrm{min}$, nebulizer pressure $60 \mathrm{psi}$ and capillary voltage - $3500 \mathrm{~V}$. The full identification of compounds was performed by comparing the retention times and mass spectra with those of standards in the same chromatographic conditions. To avoid or limit the interference from background, the multiple reactions monitoring analysis mode was used instead of single ion monitoring (e.g., MS/MS instead of MS). Calibration curves of the lactones in the range of selected concentrations $(0.02-3 \mu \mathrm{g} / \mathrm{mL})$ showed a linear correlation coefficient $\left(R^{2}>0.99\right)$.

Determination of total phenolic and flavonoidcontents

The concentration of total phenols in plant extracts was estimated by Folin-Ciocalteu procedure and the flavonoids content was estimated by the aluminium chloride colorimetric method $[16,17]$ using an Able JascoV-550 UV-Vis spectrophotometer. Total phenolic content was expressed as gallic acid equivalents (mg) in $1 \mathrm{~g}$ of dry material. Total flavonoids content was expressed as $\mathrm{mg}$ quercetin equivalents per gram dry weight of sample.

\section{Antioxidant tests}

The antioxidant activity of extracts was evaluated by DPPH radical-scavenging method [18] and reducing power assay [19]. For this, the crude methanol extracts were evaporated to dryness and dissolved in DMSO at different concentrations ranging from 0.2 to $10 \mathrm{mg} / \mathrm{mL}$. The antioxidant activities of extracts were expressed as the efficient concentration $\mathrm{EC}_{50}$ and quercetin was used as a positive control. All measurements were carried out in triplicate and results were expressed as mean value \pm standard deviation.

\section{Results and discussions}

The analysis of polyphenols

Eighteen phenolic compounds (seven phenolic acids, four quercetin glycosides, and seven flavonol and flavone 
aglycones) have been investigated in A. campestris subsp. campestris extract using a previously developed HPLC method [15]. This method allows a simultaneous analysis of different classes of polyphenols by a single column pass. The separation of examined compounds was performed in 35 min. Figures 1 and 2 show the HPLC chromatogram of the non-hydrolyzed and hydrolyzed extract of $A$. campestris. The concentrations of identified polyphenolic compounds in A. campestris extract are presented in table 1 in order of the compounds' retention time, expressed as $\mu \mathrm{g} / \mathrm{g}$ dry weight plant material.

The results show the presence of phenolic acids in the samples: $p$-coumaric acid is found in free form and in higher quantity in esterified form, gentisic and ferulic acid are only present in the hydrolyzed extract, caffeic and chlorogenic acid are both present in extracts. Caftaric and sinapic acid, hyperoside, myricetin, fisetin, quercitrin, patuletin and kaempferol were not identified in the tested extracts.

Among the analyzed flavonoids, isoquercitrin is found in high amounts in the crude methanol extract of $A$. campestris, followed by rutin and moderate quantities of luteolin, apigenin and quercetin. As expected, higher amounts of quercetin are present in the hydrolyzedextract, seeing that its glycosides were found in the crude extract. Luteolin is also present in the hydrolyzed extract.
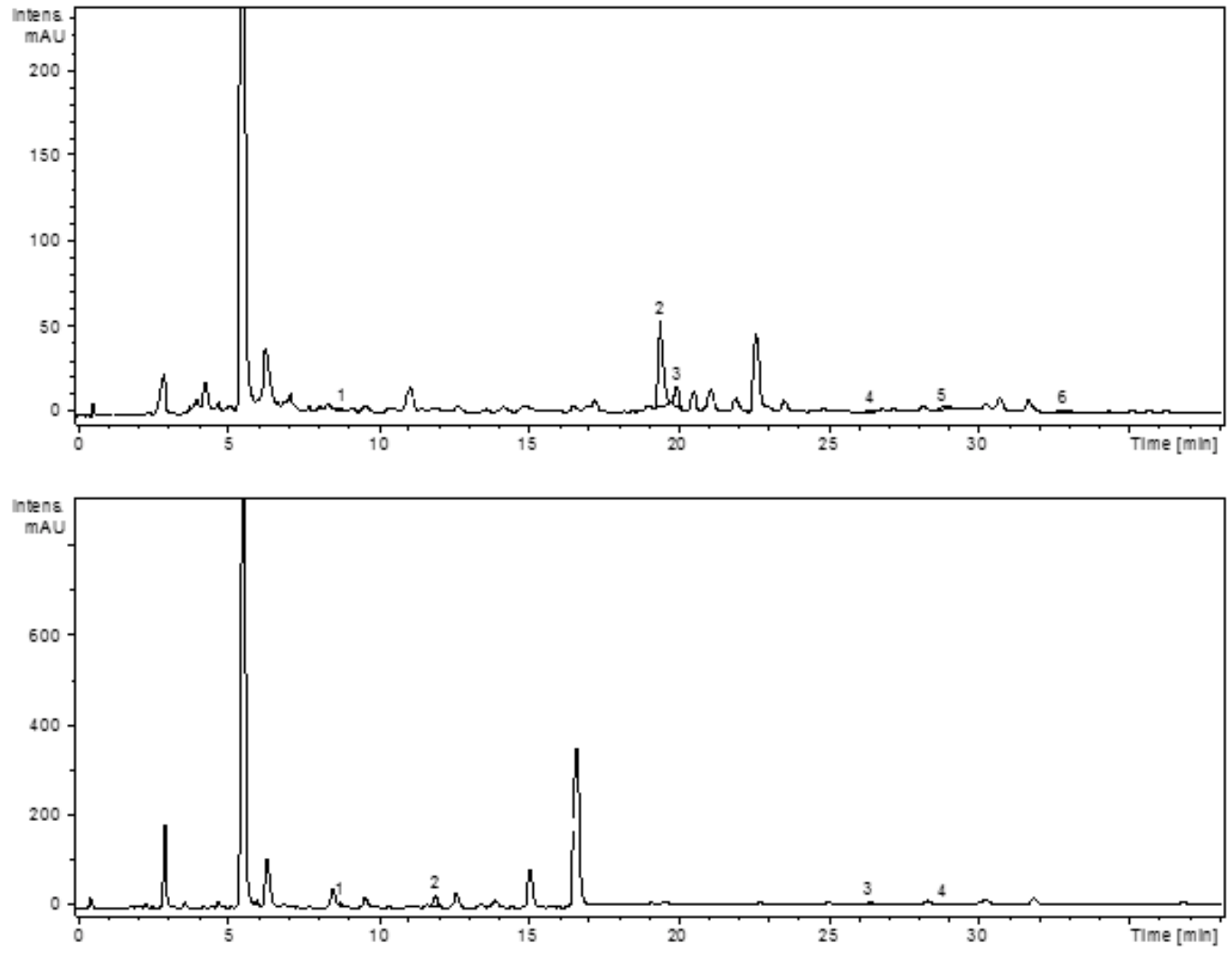

Fig.1 HPLC chromatogram of $A$. campestris extract (non-hydrolyzed): p-coumaric acid (1), isoquercitrin (2), rutoside (3), quercetin (4), luteolin (5), apigenin (6)

Fig. 2. HPLC chromatogram of $A$. campestris extract (hydrolyzed): p-coumaric acid (1), ferulic acid (2), quercetin (3), luteolin (4)

\begin{tabular}{|c|c|c|c|c|}
\hline Polyphenolic compounds & $\begin{array}{r}\mathbf{m} / \mathbf{z} \\
\text { value }\end{array}$ & $\begin{array}{r}\text { Rt } \\
(\mathrm{min})\end{array}$ & $\begin{array}{l}\text { A. campestrisextract } \\
\text { (non-hydrolyzed) }\end{array}$ & $\begin{array}{l}\text { A. campestrisextract } \\
\text { (hydrolyzed) }\end{array}$ \\
\hline Gentisic acid & 153 & 3.5 & - & 8 \\
\hline Caffeic acid & 179 & $5.6^{-}$ & - & 8 \\
\hline Chlorogenic acid & 353 & 5.6 & $*$ & $8^{---1}$ \\
\hline p-Coumaric acid & 163 & 8.7 & $18.44^{-}$ & $38.92^{-}$ \\
\hline Ferulic acid & 193 & 12.2 & - & 224.50 \\
\hline Isoquercitrin & 463 & 19.6 & $1874.80^{\circ}$ & - \\
\hline Rutin & 609 & 20.2 & 364.52 & - \\
\hline Quercetin & 301 & 26.8 & $7.88^{-}$ & 36.50 \\
\hline Luteolin & 285 & 29.1 & 46.68 & 30.1 \\
\hline Apigenin & 269 & 33.1 & 21.38 & - \\
\hline
\end{tabular}

Table 1

PHENOLIC COMPOUNDS IDENTIFIED IN A. CAMPESTRIS $(\mu \mathrm{g} / \mathrm{g}$ DW PLANT MATERIAL)

overlapping from other compounds does not allow the quantitative determination of these substances. 
The data available in the scientific literature reports the presence of luteolin and apigenin glycosides in the ethanolextract and the presence of quercetin and its glycosides in the aqueousextract of $A$. campestris from Tunisia [12]. Karabegovic et al. [20] identified in the methanol extracts of $A$. campestrisfrom Bulgaria apigenin, quercetin, rutin, hyperoside and their glycosides and also glycosides of kaempferol and luteolin. Megdiche-Ksouri et al. [11] have found rutin in the methanol crude extract and the aqueous fraction and quercetin in the methanol crude extract of $A$. campestris subsp. maritima.

\section{Caffeic and chlorogenic acids analysis}

In the previous polyphenols analysis, caffeic and chlorogenic acids - both powerful antioxidants, could not be quantified due to co-elution, so a new LC-MS method was used for their determination in plant extract.

In the aforementioned chromatographic conditions, the retention time of the chlorogenic was 2.2 min nand of caffeic acid $3.3 \mathrm{~min}$, as shown in figure 3 . Because in the ionization conditions both acids lose a proton, the ions monitored by the mass spectrometer are always in the form $[\mathrm{M}-\mathrm{H}]$; , so the ions recorded have $\mathrm{m} / \mathrm{z}=353$ for chlorogenic acid and m/z = 179 for caffeic acid. Anyway, in order to increase the selectivity and sensitivity of the method, for each compound, a second ion was monitored from the MS/MS spectrum: $\mathrm{m} / \mathrm{z} 191$ for chlorogenic acid and $\mathrm{m} / \mathrm{z} 135$ for caffeic acid.

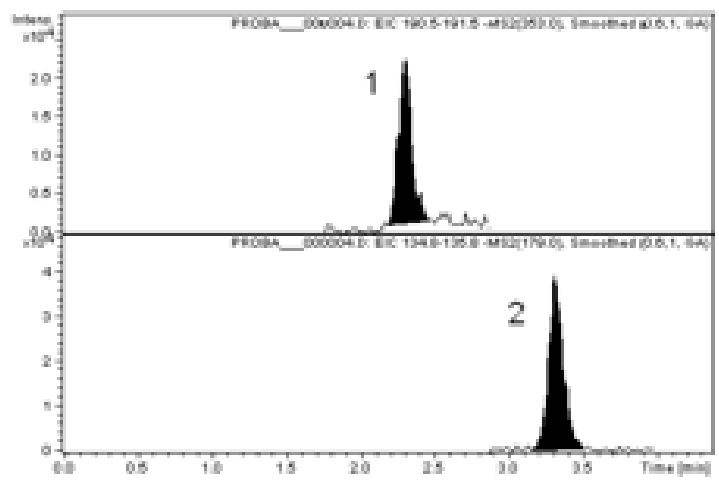

Fig. 3. MS chromatograms of chlorogenic (1) and caffeic (2) acids

Theseions were further used for the quantitative determination of these compounds, seeing that the intensity of ions in the mass spectrum is proportional to the concentration of the substance in the sample. The nativespecies contains higher amounts of chlorogenic acid $(8197.2 \mu \mathrm{g} / \mathrm{g} \mathrm{dw}$ ) than caffeic acid $(61.6 \mu \mathrm{g} / \mathrm{g} \mathrm{dw})$ in accord to the findings of Pereira et al. who reported the presence of both hydroxycynnamic acids in $A$. campestris subsp. maritime [6].

To the best of our knowledge, our study identified and quantified for the first time isoquercitrin, caffeic acid, chlorogenic acid, ferulic acid and p-coumaric acid in $A$. campestris subsp. campestris samples. It also qualitatively identified gentisic acid in the hydrolyzed extract.

\section{The analysis of methoxylated flavones}

Considering the fact that methoxylated flavones, found generally as aglycones in the epicuticular wax, are bioactive compounds frequently identified in species from Asteraceae family [21], their determination isof interest from the point of view of a medicinal plant.

Thus, a new LC-MS method was developed in order to assess the presence of six methoxylated flavones in the plant extract: jaceosidin, hispidulin, eupatilin, eupatorin, casticin and acacetin. The analytes eluted in less than 10 min in the chosen chromatographic conditions, as shown in figure 4 . In the process of MS analysis, the pseudomolecular ions of the flavones have been fragmented, and based on their daughter ions from the MS spectrum (table 2) the extracted chromatograms of each compound were constructed for quantification.

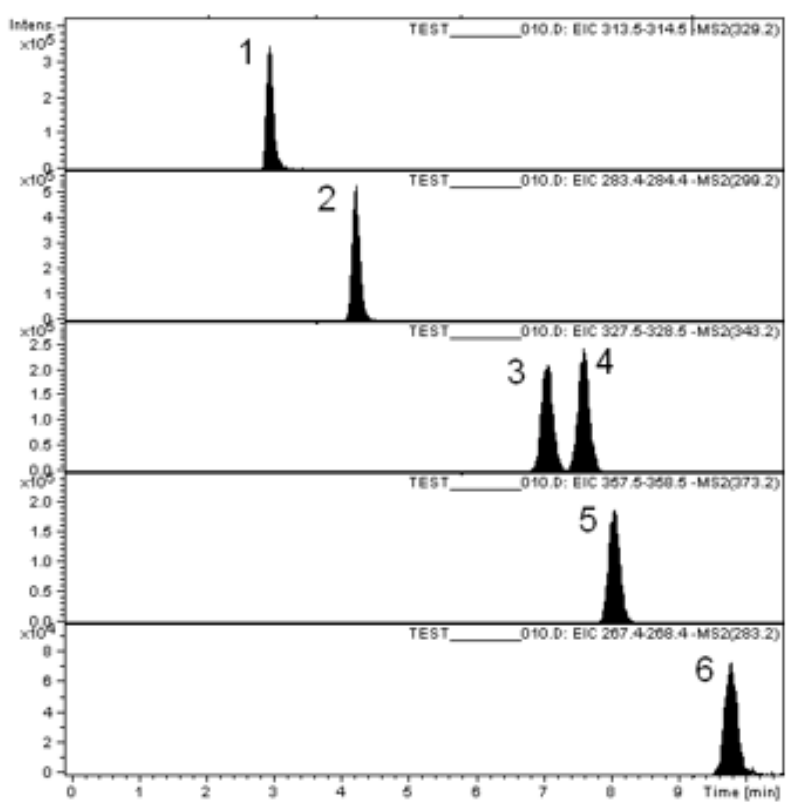

Fig.4. MS chromatograms of analyzed flavones: jaceosidin (1), hispidulin (2), eupalitin (3), eupatorin (4), casticin (5) and acacetin (6)

Table 2

CHARACTERISTIC IONS OF STANDARD FLAVONES IN FULL SCAN AND SPECIFIC IONS USED IN QUANTIFICATION

\begin{tabular}{|c|c|c|c|c|}
\hline Compound & $\begin{array}{l}\mathrm{R}_{\mathrm{T}} \\
(\mathrm{min})\end{array}$ & 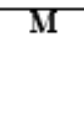 & {$[\mathrm{M}-\mathrm{H}]^{-}$} & $\begin{array}{c}\text { Monitored } \\
\text { ions/fragments }\end{array}$ \\
\hline Jaceosidin & 2.9 & 330.3 & 329.3 & 314 \\
\hline Hispidulin & 4.2 & 300.2 & 299.2 & 284 \\
\hline Eupalitin & $7.05^{\circ}$ & 344.3 & 343.3 & 328 \\
\hline Eupatorin & 7.6 & 344.3 & 343.3 & 328 \\
\hline Casticin & 8.05 & 374.3 & 373.3 & 358 \\
\hline Acacetin & 9.8 & 284.3 & 283.3 & 268 \\
\hline
\end{tabular}

All six compounds selected for this analysis are known for their pharmacological properties, mainly antitumor, antiinflammatory, antioxidant, antimicrobial and anti-ulcer [22, 23]. Eupatorin, casticin and acacetin were determined for the first time in $A$. campestris, while jaceosidin was not present in the plant extract. Eupatilin and hispidulin were previously reported in Tunisian and Bulgarian plants, respectively $[1,20]$. The compounds were identified in moderate amounts, eupatorin having the highest concentration in plant $(100.90 \mu \mathrm{g} / \mathrm{g} \mathrm{dw})$ and acacetin the lowest $(1.89 \mu \mathrm{g} / \mathrm{g} \mathrm{dw})$. The eupatilin content in plant was $40.33 \mu \mathrm{g} / \mathrm{g}$, hispidulin $27.58 \mu \mathrm{g} / \mathrm{g}$ and casticin $24.39 \mu \mathrm{g} / \mathrm{g}$ $d w$. Methoxylated flavonoids are promising therapeutic candidates due to their lipophilic nature and increased metabolic stability that results in high oral bioavailability compared to other polyphenols [23].

\section{The analysis of phytosterols}

In order to identify the sterols present in the plant extract, a previously reported method LC-MS method was used 
[15]. The ions monitored in the MS assay are presented in table 3. The ions detected by the mass-spectrometer are in the form $\left[\mathrm{M}-\mathrm{H}_{2} \mathrm{O}+\mathrm{H}\right]+$ because in the ionization conditions all sterols have lost a water molecule. The specific ions of the five standard sterols have been fragmented and the extracted chromatograms of each compound were drawn. The method was also applied for the quantification of phytosterols, because the intensity of major ions in the mass spectrum is proportional to the concentration of the substance in the sample.

Stigmasterol, $\beta$-sitosterol and campesterol were quantified in $A$. campestris extract, while brassicasterol and ergosterol were not present. None of the sterol compounds were previously reported for $A$. campestris. $\beta$ Sitosterol was the dominant sterol $(159.84 \mu \mathrm{g} / \mathrm{g} \mathrm{dw})$, followed bystigmasterol $(27.38 \mu \mathrm{g} / \mathrm{g} \mathrm{dw}$ ) and low amounts of campesterol $(4.10 \mu \mathrm{g} / \mathrm{g} \mathrm{dw})$. Plant sterols have cholesterol-lowering effect and offer protection against cardiovascular diseases; they also exhibit a potent antiinflammatory activity and manifest anticancer properties [24].

The analysis of sesquiterpene lactones

Sesquiterpene lactones are an important class of secondary metabolites specific to Artemisia species, structurally divers and synthesized in response to biotic or abiotic stress [25]. For that reason, we attempted the identification of some compounds in this group by developing a new LC-MS method in order to assess the presence of six sesquiterpene lactones: vulgarin, $\alpha$ - santonin, dehidroleucodine, artemisinin, costunolide and alantolactone. The analytes eluted in less than 7 minutes in the selected chromatographic conditions, as presented in figure 5.

MS detection showed the parent-ions of analyzed lactones. Apart for vulgarin, in each case the expected ion was observed (table 4). Vulgarin suffers dehydration during the ionization process, so the scanned ion has $\mathrm{m} / \mathrm{z} 247.3$ and not 265.3, as expected. In this case, the ion with $\mathrm{m} / \mathrm{z}$ 247.3 was further fragmented in order to obtain the MS/MS spectrum.

The specific ions of the six standard lactones have been fragmented and the extracted chromatograms of each compound were constructed for quantification.

From the six standards used in analysis of sesquiterpene lactones, only $\alpha$-santonin was found in small amounts in A. campestris $(0.24 \mu \mathrm{g} / \mathrm{g} \mathrm{dw})$. $\alpha$-Santonin is a known antihelmintic drug, fallen out of used due to severe side effects and development of modern safer de-worming drugs. It also manifests anti-inflammatory, analgesic, antipyretic and mild anticancer effect and in recent years has become the parent molecule for the synthesis of new anticancer compounds [26]. Although $\alpha$-santonin is present in numerous Artemisia species, notably in A. cina - the botanical source of the compound, its concentration in A. campestriswas never reported. However, the amount of santonin found in $A$. campestris is too small to be considered for extraction or to pose a health risk in phytotherapeutic use.

\begin{tabular}{|c|c|c|c|}
\hline Compound & $\begin{array}{r}\mathrm{R}_{\mathrm{T}} \\
(\mathrm{min})\end{array}$ & M & $\begin{array}{l}\text { Specific ions for identification } \\
\text { Ion }\left[\mathrm{M}-\mathrm{H}_{2} \mathrm{O}+\mathrm{H}^{+}\right]>\text {Ions from spectrum }\end{array}$ \\
\hline Ergosterol & 3.2 & 396 & $379>158.9 ; 184.9 ; 199 ; 213 ; 225 ; 239 ; 253 ; 295 ; 309 ; 323$ \\
\hline Brassicasterol $^{-}$ & 3.9 & $398^{-}$ & $381>201.3 ; 203.3 ; 215.2 ; 217.3 ; 241.2 ; 255.3 ; 257.4 ; 271.1 ; 297.3 ; 299.3$ \\
\hline Stigmasterol & 4.9 & 412 & $395>255 ; 297 ; 283 ; 311 ; 241 ; 201^{-}$ \\
\hline Campesterol & 4.9 & $400^{-}$ & $383>147 ; 149 ; 161 ; 175 ; 189 ; 203 ; 215 ; 229 ; 243 ; 257^{-}$ \\
\hline$\beta$-Sitosterol & 5.7 & $414^{-}$ & $397>160.9 ; 174.9 ; 188.9 ; 202.9 ; 214.9 ; 243 ; 257 ; 287.1 ; 315.2$ \\
\hline
\end{tabular}

Table 3

CHARACTERISTIC IONS OF STANDARD STEROLS IN FULL SCAN AND SPECIFIC IONS USED IN QUANTIFICATION

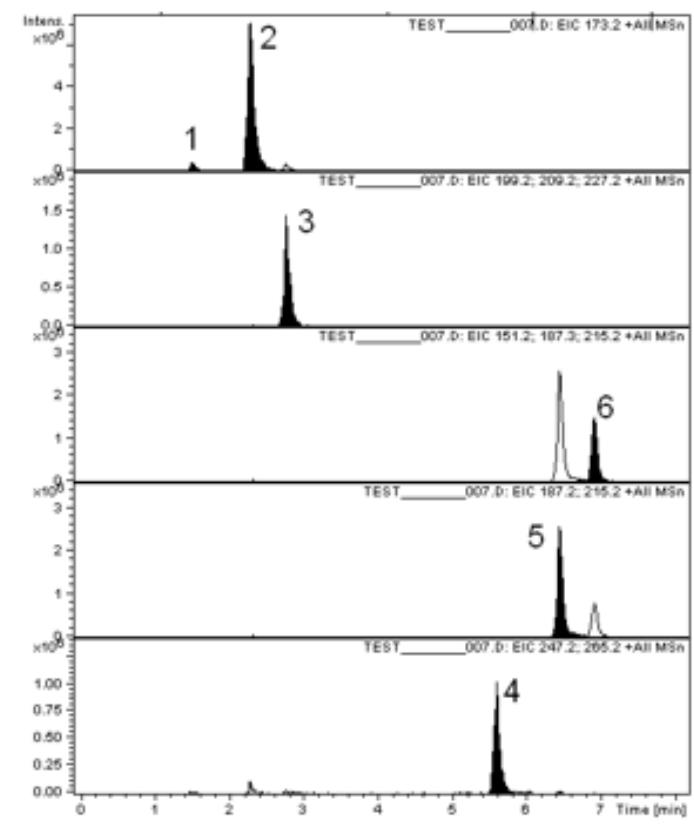

Table 4

CHARACTERISTIC IONS OF STANDARD LACTONES IN FULL SCAN AND SPECIFIC IONS USED IN QUANTIFICATION

\begin{tabular}{|c|c|c|c|c|}
\hline Compound & $\mathrm{R}_{\mathrm{T}}(\mathrm{min})$ & $M$ & $\mathrm{M}+\mathrm{H}^{+}$ & Monitored ions/fragments \\
\hline Vulgarin & 1.45 & 264.3 & $265.3 / 247.3$ & 173.2 \\
\hline$\alpha$-Santonin & $2.20^{-}$ & $246.3^{-}$ & 247.3 & $173.2^{-}$ \\
\hline Dehydroleucodine & $2.70^{-}$ & 244.3 & 245.3 & $199.2,209.2,217.2,227.2$ \\
\hline Artemisinin & $5.50^{\circ}$ & 282.3 & 283.3 & $247.2,265.2$ \\
\hline Costunolide & 6.40 & 232.3 & 233.3 & $187.3,215.2$ \\
\hline Alantolactone & $6.85^{\circ}$ & 232.3 & 233.3 & $151.2,187.3,215.2$ \\
\hline
\end{tabular}

Fig. 5. MS chromatograms of analyzed lactones: vulgarin

(1), $\alpha$-santonin (2), dehydroleucodine (3), artemisinin

(4), costunolide (5), alantolactone (6) 


\section{Total phenols and total flavonoids content}

Artemisia campestris extract contains significant amounts of phenolic compounds, having a total phenolic content of $114.61 \mathrm{mg} / \mathrm{g} \mathrm{dw}$. This result is comparable to levels of polyphenols found in A. campestris subsp. maritima (119 - $134 \mathrm{mg} / \mathrm{g} \mathrm{dw}$ ) [6] and superior to those reported for North-African plants [9, 27].Total flavonoid content, expressed as quercetin equivalents, was 17.99 $\mathrm{mg} / \mathrm{g} \mathrm{dw}$, similar to values reported in literature $[9,13]$.

\section{Antioxidant activity}

The radical scavenging activity of $A$. campestris extract varied depending on concentration (fig. 6). Thus, the extract exhibited a scavenging activity of $9.87 \pm 0.18 \%$ at a concentration $5.20 \mu \mathrm{g} / \mathrm{mL}$; at the same concentration, quercetin inactivated the DPPH radical in high percentage $(75.64 \pm 0.46 \%)$. At a concentration $83.33 \mu \mathrm{g} / \mathrm{mL}$, the activity increased, reaching similar values for both extract $(92.64 \pm 0.07 \%)$ and quercetin $(96.34 \pm 0.31 \%)$. The $A$. campestris extract $\left(\mathrm{EC}_{50}=28.0 \pm 0.2 \mu \mathrm{g} / \mathrm{mL}\right.$ ) was less active than quercetin $\left(\mathrm{EC}_{50}=3.1 \pm 0.0 \mu \mathrm{g} / \mathrm{mL}\right)$ as scavenger of DPPH radicals. Still, taking into account the $\mathrm{EC}_{50}$ values and the fact that quercetin is a pure compound known for its antioxidant properties, we can estimate that the field wormwood extract shows a very good scavenging activity against DPPH radicals.

The ability of $A$. campestris extracts to scavenge free radicals is also supported by other studies, as shown in literature. The $\mathrm{EC}_{5}$ values vary widely depending on the type of extract, subspecies and pedoclimatic conditions that directly influence the chemical composition. For example, Romanian plants showed similar scavenging ability to the Bulgarian species collected from a mountain area (19.8-23 $\mu \mathrm{g} / \mathrm{mL}$ for the methanol extract) [20]. On the other hand, different results were obtained on plants from Tunisia or Algeria probably belonging to the subspecies maritima: $9.61 \mathrm{mg} / \mathrm{L}$ in $80 \%$ methanol extract [27], $0.03 \mathrm{mg} / \mathrm{mL}$ in $70 \%$ ethanol extract [9] and $6 \mathrm{ig} / \mathrm{mL}$ in crude methanol extract [11].

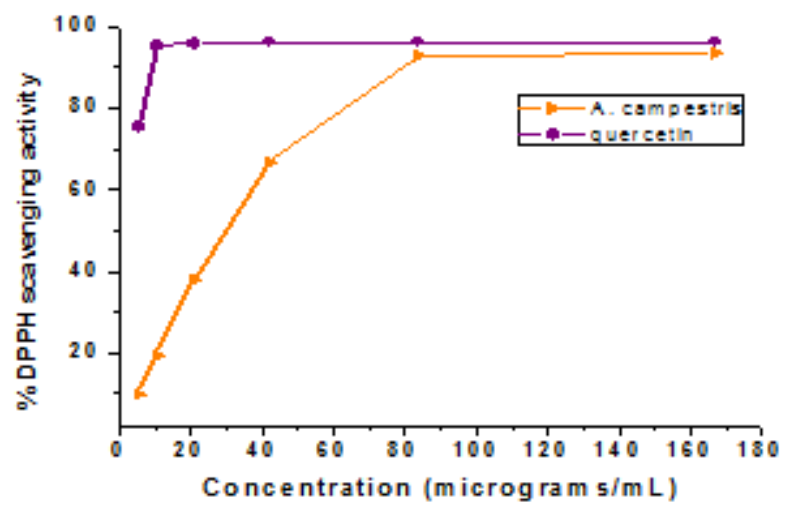

Fig.b. kaaıcal scavengıng activity or $A$. campestris extract comparea to quercetin

The reducing power determination is used in order to assess the ability of a substance to donate an electron. The antioxidant compounds in the extract will reduce potassium ferricyanide to ferrocyanide which, in the presence of ferric chloride, forms ferric ferrocyanide, a blue complex. In the reducing power assay, A. campestris extract proved to be a good reducing agent $\left(\mathrm{EC}_{50}=18.05\right.$ $\pm 0.17 \mu \mathrm{g} / \mathrm{mL}$ ), though less active compared to the positive control, quercetin $\left(\mathrm{EC}_{50}=2.78 \pm 0.00 \mu \mathrm{g} / \mathrm{mL}\right)$. The same test, carried out on the methanol crude extract of aerial parts from Tunisian A. campestris subsp. maritima, resulted in $\mathrm{EC}_{50}=110 \mu \mathrm{g} / \mathrm{mL}$, inferior to that of control substance, ascorbic acid [11].

\section{Conclusions}

Our study reports for the first time the presence of eupatorin, acacetin, casticin, stigmasterol, â-sitosterol, campesterol, and gentisic acid in A. campestris. All the above-mentioned compounds and others already acknowledged manifest different pharmacological activities that contribute to the therapeutic effect of the plant extract. The phytochemical study was carried out through LC-MS analyses and two new methods were developed for the analysis of methoxylated flavones and sesquiterpene lactones. Antioxidanttests carried out in vitro on $A$. campestris plants confirm the fact that it has antioxidant activity and could be used as a potential therapy in oxidative stress related diseases.

\section{References}

1. METOUI, R., BOUAJILA, J., ZNATI, M., CAZAUX, S. et al., Cell Mol Biol (Noisy-le-grand) 63, no. 11, 2017, p. 86.

2.ALI, M.Y., JANNAT, S., JUNG, H.A., CHOI, R.J .et al., Asian Pac. J. Trop. Med. 9, no. 2, 2016, p. 103

3.SALAHORU, P, GHICIUC, C.M., GRIGORESCU, C., HINGANU, M.V., LUPUSORU, C.E., Rev. Chim.(Bucharest), 69, no.7, 2018, p. 2251.

4.SARBU, I., STEFAN, N., OPREA, A., Vascular plants of Romania. An illustrated field guide. Publishing House Victor B Victor, Bucharest, 2013.

5.AL-SNAFI, A.E., Asian J. Pharm. Res. 5, no.2, 2015, p. 88.

6.PEREIRA C.G., BARREIRA, L., BIJ TTEBIER, S., PIETERS, L., et al., Scientific Reports 8, 2018, p. 4689.

7.GHORAB, H., LAGGOUNE, S., KABOUCHE, A., SEMRA, Z., KABOUCHE, Z., Der Pharmacia Lettre 5, no. 2,2013, p. 189.

8.BADEA, M.L. Doctoral Thesis Researches on the secretory tissue structure, composition of volatile oil and chorology on some species of Artemisia in Romania,University of Agricultural Sciences and Veterinary Medicine, Bucharest, 2011.

9.BOULANOUAR, B., ABDELAZIZ, G., AAZZA, S., GAGO, C., GRACA MIGUEL, M., Ind. Crop Prod. 46, 2013, p. 85.

10.CARVALHO, I.S., TEIXEIRA, M.C., BRODELIUS, M., LWT - Food Sci. Technol. 44, no. 1, 2011, p. 293.

11.MEGDICHE-KSOURI, W., TRABELSI, N., MKADMINI, K., BOURGOU, S., et al., Ind. Crops Prod. 63, 2015,p. 104.

12.AKKARI, H., RTIBI, K., B'CHIR, F., REKIK,M. et al., Vet. Res. Commun 38, no. 3, 2014, p. 249.

13.SEFI, M., FETOUI, H., MAKNI, M., ZEGHAL, N., Food Chem. Toxicol. 48, no. 7, 2010, p. 1986.

14.KHALAF, I., VLASE, L., LAZAR, D., CORCIOVA, A. et al. Farmacia 58, no. 4, 2010, p. 416

15.KHALAF, I., VLASE, L., IVANESCU, B., LAZAR, D., CORCIOVA, A. Studia UBB Chemia LVII, 2, 2012, p. 113.

16.CASACCHIA, T., D'IPPOLITO, C., TOMA, C.C., UZUNOV, D. et al. Rev. Chim.(Bucharest), 68, no. 11, 2017, p. 2523.

17.POP, C.E., PARVU, M., ARSENE, A.L., PARVU, A.E. et al. Farmacia 65, no. 4,2017, p. 624.

18.ORODAN, M., VODNAR, D.C., TOIU, A.M., POP, C.E. et al. Farmacia 64, no. 2, 2016, p. 224.

19.IANCU, C., CIOANCA, O., MIRCEA, C., MOCANU, M., HANCIANU, M. Farmacia 64, no. 3, 2016, p. 333.

20.KARABEGOVIC, I., NIKOLOVA, M., VELICKOVIC, D., STOJ ICEVIC, S. et al. Chinese J. Chem. Eng. 19, no. 3, 2011, p. 504.

21.IVANESCU, B., TUCHILUS, C., CORCIOVA, A., LUNGU, C. et al. Farmacia, 66, no. 2, 2018, p. 282.

22.FERREIRA, J.F.S., LUTHRIA, D.L., SASAKI, T., HEYERICK, A. Molecules 15, no. 5, 2010, p. 3135.

23.WALLE, T. Semin Cancer Biol. 17, no. 5, 2007, p. 354.

24.OGBE, R.J., OCHALEFU, D.O., MAFULUL, S.G., OLANIRU, O.B. Asian J. Plant Sci. Res. 5, no. 4, 2015, p. 10.

25.CHADWICK,M., TREWIN, H., GAWTHROP, F., WAGSTAFF, C.Int. J. Mol. Sci. 14, no. 6, 2013, p. 12780.

26. KHAZIR, I., SINGH, P.P., REDDY, D.M., HYDER, l.et al., Eur. J. Med. Chem. 63, 2013, p. 279

27.DJ ERIDANE, A., YOUSFI, M., BRUNEL, J.M., STOCKER, P. Food Chem. Toxicol. 48, no. 10, 2010, p. 2599.

Manuscript received:21.03.2018 